\title{
A Simple and Effective Liquid-Liquid-Liquid Microextraction Method with Ultraviolet Spectrophotometric Detection for the Determination of Bisphenol A in Aqueous Matrices and Plastic Leachates
}

\author{
Ricardo D. Huelsmann ${ }^{\circledR a, b}$ and Edmar Martendal ${ }^{\circledR} *, a$ \\ aDepartamento de Química, Universidade do Estado de Santa Catarina, 89219-710 Joinville-SC, Brazil \\ ${ }^{b}$ Departamento de Química, Universidade Federal de Santa Catarina, 88040-900 Florianópolis-SC, Brazil
}

\begin{abstract}
This study shows the development and application of an analytical method for the determination of bisphenol A (BPA) in aqueous samples such as tap, river and mineral water and plastic leachates, based on an extensive literature search to understand the gaps for the determination of BPA in aqueous samples. We found that most of the methods in the literature employ some chromatographic strategy, and, to a much lesser extent, non-chromatographic instrumentation. In this scenario, we show an ultraviolet spectrophotometric-based method that can be used for routine analysis. Sample preparation was conducted by means of solvent extraction followed by back-extraction into an alkaline aqueous solution (liquid-liquid-liquid microextraction) and the detection was performed by UV spectrophotometry at $294 \mathrm{~nm}$. Optimization of variables affecting both extraction and back-extraction was conducted, and the optimal extraction conditions were obtained: $85 \mathrm{~mL}$ aqueous sample buffered at $\mathrm{pH} 10$, ionic strength adjusted with $\mathrm{NaCl}$ to a $2 \mathrm{~mol} \mathrm{~L}^{-1}$ final concentration, extraction with $6 \mathrm{~mL}$ of ethyl ether for $10 \mathrm{~min}$ and back-extraction into $0.5 \mathrm{~mL}$ of $2 \mathrm{~mol} \mathrm{~L}^{-1}$ aqueous $\mathrm{NaOH}$. The following quality parameters were obtained: determination coefficient $\left(\mathrm{R}^{2}\right)>0.999$, intra and inter-day repeatability better than $7.8 \%$ and 300 enhancement factor. The method was applied in different aqueous samples with excellent recovery and precision results, and no BPA was detected in natural water, even with the excellent limit of detection $\left(3.5 \mu \mathrm{g} \mathrm{L}^{-1}\right)$ and limit of quantification obtained. Limitations of this method involve analysis of samples with humic acid concentrations higher than $2 \mathrm{mg} \mathrm{L}^{-1}$ or high concentration of phenols and/or phthalate esters.
\end{abstract}

Keywords: bisphenol A, spectrophotometry, liquid-liquid-liquid microextraction

\section{Introduction}

Contemporary productive society seeks constant productivity increase and profit maximization, which can use means with an exacerbated use of compounds and products capable of bringing risks to the health of living organisms, through contamination of water, air and soil. Compounds of different classes have been distributed at great speed in the environment, reaching the human being, animals and plants via different routes. The unrestrained presence and high amounts of plasticizers, personal care products, hormones, drugs, pesticides, nanoparticles and flame retardants have been extensively discussed and studied by several research groups worldwide, ${ }^{1}$ given their known and potent deleterious effects to various organisms. The problem with the class of plasticizers, specifically,

*e-mail: edmar.martendal@udesc.br has been widely discussed, involving several compounds known to scientists, government and international media, which produce materials to alert the population about the toxicity of certain compounds. Among these compounds is bisphenol A (BPA).

BPA (2,2-bis(4-hydroxyphenyl propane)) is a diphenol applied in several matrices, processes and products. The industrial production of BPA is estimated to reach 10 million tons per year in 2022, being 8 million in $2016 .^{2}$ About $95 \%$ of BPA production is used in the polymer industry, including polycarbonate and epoxy resins. ${ }^{3}$ Thus, BPA is applied to several everyday products such as water bottles, electronic equipment, paper and toys. ${ }^{4} \mathrm{BPA}$ is considered an endocrine disrupter, particularly capable of binding and activating estrogen receptors, and its estrogenic properties have been recognized since 1938 by Dodds et al. ${ }^{5}$ This compound is considered a synthetic xenoestrogen and, when in contact with the human organism, it can 
deregulate the endocrine functions by mimetizing or blocking endogenous hormones. ${ }^{6}$

Since water is a widely available matrix that can be the final destination of domestic and industrial waste, we must develop effective analytical methods for the monitoring of natural waters such as rivers, lakes and seas, as well as treated water samples, to verify the potential toxicity to which organisms are exposed. This statement gets clearer after searching the literature for methods for the determination of BPA in aqueous samples in the last 20 years (1999-2018), considering chromatographic and spectrometric methods. In total, 148 methods were found, and this number is increasing over the years (Figure S1, Supplementary Information (SI) section). In terms of sample preparation methods, we verified that about 70\% of the studied methods are based on the retention of BPA by a solid phase (Figure S2, SI section), in which solidphase extraction (SPE) corresponds to half of the analyzed methods, including new approaches with molecularly printed polymers and magnetic particles. Solid phase microextraction (SPME) and stir-bar sorptive extraction (SBSE) represent 13 and $6 \%$ of the total, respectively. On the other hand, $97 \%$ of the total of the articles used chromatographic methods. Two-thirds of all methods use liquid chromatography (LC) and 25\% gas chromatography (GC), followed by capillary electrophoresis (CE) and supercritical fluid chromatography (SFC). Only $3 \%$ of the methods used non-chromatographic detection alternatives, including fluorimetry, Raman spectrometry and UV-Vis spectrophotometry (Figure S3, SI section).

Other information involving the method development such as quantity of samples, sample preparation time, time required for instrumental analysis, sample volume and analytical parameters of merit were also investigated and are shown in the SI section (Figures S4 to S8). The limit of detection (LOD) of methods for environmental analysis are low, commonly lesser than $10 \mu \mathrm{g} \mathrm{L}^{-1}$, as can be seen in the Figure S5 (SI section), since the concentration of pollutants are in this concentration range.

Regarding the study of potential interferents, even considering that most of the searched works use highly selective chromatographic methods, this observation is very important for an analytical method, since it makes method limitations clearer, allowing the analyst to decide if the method is reliable for a given sample. Interferents may cause either selectivity interference or matrix effects, especially in a complex environmental water sample. As shown in Figure S9 (SI section), $81 \%$ of the articles do not study the response of their methods in relation to the presence of interferents. Several authors ${ }^{7-10}$ who study the presence of interferents are especially careful with the presence of humic acid, a component that may be present in environmental samples in the 0 to $10 \mathrm{mg} \mathrm{L}^{-1}$ range. Other studies ${ }^{11-13}$ evaluate the presence of other compounds in the sample, such as BPA analogs. We must note that all studies that evaluate interferents were conducted using a univariate approach. This means that they perform tests considering only the presence of one interferent at a time, not considering the possibility that they may all exist simultaneously in the sample, which is understood to be quite plausible in the case of natural water samples.

One can emphasize the small diversity of strategies that do not use chromatographic methods. However, the separation methods, although very relevant, usually present high cost of acquisition and maintenance when compared with spectrometric methods. Considering the UV-Vis spectrophotometry methods, all the searched articles ${ }^{11,14,15}$ report the use of the visible region, displacing the wavelength of maximum absorption of BPA through different mechanisms. The paper by Xu et al..$^{14}$ uses the interaction of BPA with gold nanoparticles coated with cysteamine, allowing the determination of BPA at $680 \mathrm{~nm}$. Yildırım et al..$^{15}$ performed the preconcentration of BPA based on its complexation with colorimetric reagent (3-methylamino-7-dimethylaminophenothiazin-5-ium chloride in the presence of cetyltrimethylammonium bromide), by cloud point extraction, enabling its measurement at $643 \mathrm{~nm}$. The last alternative method to determine BPA by spectrophotometry, developed by $\mathrm{Xu}$ et al. ${ }^{11}$ is based on the diazotization reaction of BPA with sulfamethoxazole, detecting a maximum absorbance at $445 \mathrm{~nm}$. The limits of detection obtained by the authors in these methods were $0.11 \mu \mathrm{g} \mathrm{L}{ }^{-1}$ for Xu et al. ${ }^{14} 0.35 \mu \mathrm{g} \mathrm{L}^{-1}$ for Yildirin et al. ${ }^{15}$ and $50 \mu \mathrm{g} \mathrm{L}^{-1}$ for Xu et al. ${ }^{11}$

In this scenario, this study proposes the development of a novel low-cost analytical method for BPA determination in aqueous samples applying a very simple sample preparation procedure based on solvent extraction followed by a back-extraction of the analyte into an aqueous alkaline microvolume (liquid-liquid-liquid microextraction), and detection using an inexpensive and highly available UV-Vis spectrophotometer (LLLME-UV). Optimization of extraction and back-extraction variables were carried out, and a multivariate approach was performed for the first time to study the effect of the concomitant presence of humic acid, phenols and phthalate esters in two different BPA concentration levels. The main quality parameters were determined, and six samples were subjected to the proposed method. Samples containing the analyte were also subjected to gas chromatography-mass spectrometry (GC-MS) analysis to confirm analyte identity and concentration. 


\section{Experimental}

\section{Reagents and preparation of solutions}

A BPA stock solution was prepared by weighing $100.0 \mathrm{mg}$ of the pure solid (Sigma-Aldrich, Saint Louis, USA) and dissolved with high-performance liquid chromatography (HPLC)-grade ethanol (Tedia, Fairfield, USA) for a $10.00 \mathrm{~mL}$ final volume. The aqueous sample solutions were prepared with water obtained on a reverse osmosis system RQ Evolution RO 0410 (Permution, Curitiba, Brazil) with conductivity below $1.0 \mu \mathrm{S} \mathrm{cm}^{-1}$.

The Britton-Robinson buffer (BR buffer) was prepared from analytical grade glacial acetic acid, potassium dihydrogen phosphate and boric acid (Vetec, Rio de Janeiro, Brazil), each component at $0.4 \mathrm{~mol} \mathrm{~L}^{-1}$ final concentration. The required sample $\mathrm{pH}$ was adjusted by adding $6.0 \mathrm{~mol} \mathrm{~L}^{-1}$ solutions of hydrochloric acid (Neon Comercial, São Paulo, Brazil) and/or $6.0 \mathrm{~mol} \mathrm{~L}^{-1}$ sodium hydroxide (Biotec, Pinhais, Brazil) by using a pH meter (model pH 510 Basic, Oakton, USA). Sodium chloride (Biotec, Pinhais, Brazil) was used to adjust ionic strength of the samples. Organic solvents (acetone, ethyl ether, chloroform, hexane and toluene) used were all HPLC-grade purity (Tedia, Fairfield, USA).

A solution containing six phthalate esters was prepared from standard CRM48805 batch XA25890V from SigmaAldrich (Saint Louis, USA), diluted to $3.40 \mathrm{mg} \mathrm{L}^{-1}$ (total phthalate concentration) with ethanol. A solution containing eleven phenol mixture was prepared from standard (CRM 48866 batch LC12991V, Sigma-Aldrich, Saint Louis, USA) and diluted with ethanol to $1.70 \mathrm{mg} \mathrm{L}^{-1}$ as the final total phenol concentration. Humic acid solution at $1.00 \mathrm{~g} \mathrm{~L}^{-1}$ was prepared by diluting the pure compound (Sigma-Aldrich, Saint Louis, USA) in $0.01 \mathrm{~mol} \mathrm{~L}^{-1} \mathrm{NaOH}$.

When GC-MS was used, BPA contained in the ether extract obtained in the method (previous to back-extraction) was submitted to derivatization using pyridine and $\mathrm{N}, \mathrm{O}$-bis(trimethylsilyl)trifluoroacetamide (BSTFA) containing 1\% trimethylchlorosilane (TMSCl) obtained from Sigma-Aldrich (Saint Louis, USA). For the derivatization reaction, $170 \mu \mathrm{L}$ of the ether extract was allowed to evaporate at room temperature. To the dried extract, $50 \mu \mathrm{L}$ pyridine and $50 \mu \mathrm{L}$ BSTFA were added into $2 \mathrm{~mL}$ screw capped vial, which was kept closed for $30 \mathrm{~min}$. This solution was analyzed by GC-MS in the conditions given in "Instrumentation" sub-section.

Instrumentation

A UV-Vis spectrophotometer Spectroquant Pharo 300 (Merck, Darmstadt, Germany) was employed for all spectrophotometric analyses. It is equipped with a simple beam system and a xenon lamp; the working range is 190 and $900 \mathrm{~nm}$ with a $1 \mathrm{~nm}$ resolution.

The verification of the selectivity of the proposed method was conducted using a GCMS-QP2010 Ultra (Shimadzu, Kyoto, Japan) gas chromatograph coupled to mass spectrometer, operating with ultra-pure helium gas as mobile phase, AOC-20i automatic sampler (whose operating characteristics are shown in Table S2, SI section) and split-splitless injector. As a stationary phase, the HP-5ms column (Agilent Technologies, Santa Clara, USA), $30 \mathrm{~m}$ long, $0.25 \mathrm{~mm}$ internal diameter and $0.25 \mu \mathrm{m}$ stationary phase was used, which was composed of $95 \%$ dimethyl/5\% diphenyl polysiloxane. The quadrupole mass analyzer used has a unitary mass resolution. Data acquisition by the instrument was performed in the full mass scanning mode, in the $m / z, 40-400$ range. The temperatures used were: injection, interface and source of ions, respectively, 300,280 , and $200{ }^{\circ} \mathrm{C}$; oven temperature programming: $60{ }^{\circ} \mathrm{C}$ for $0.5 \mathrm{~min}$, heating to $300{ }^{\circ} \mathrm{C}$ at $45^{\circ} \mathrm{C} \mathrm{min}-1$, remaining at $300{ }^{\circ} \mathrm{C}$ for $1.17 \mathrm{~min}$, totaling a 7 min run. The mobile phase flow (99.999\% pure helium) was $1.70 \mathrm{~mL} \mathrm{~min}{ }^{-1}$, except for the first minute, in which the flow rate was $3.6 \mathrm{~mL} \mathrm{~min}^{-1}$, corresponding to a $200 \mathrm{kPa}$ pressure. The injection was performed in splitless mode for 1 min, followed by a 1:5 split ratio for the rest of the run.

\section{Sample preparation procedure}

Sample preparation consisted of $85 \mathrm{~mL}$ of sample added in a $100 \mathrm{~mL}$ glass volumetric flask. The ionic strength and sample $\mathrm{pH}$ are adjusted to the desired value using solid $\mathrm{NaCl}$ and $5 \mathrm{~mL}$ of $0.4 \mathrm{~mol} \mathrm{~L}^{-1} \mathrm{BR}$ buffer previously adjusted to the desired $\mathrm{pH}$, respectively. The final volume of the conditioned sample is approximately $100 \mathrm{~mL}$. Then, $6 \mathrm{~mL}$ of organic solvent for extraction are added in the same flask, which occurs for 10 min under vigorous magnetic stirring. The organic extract separates rapidly, being removed from the flask (with a little of the aqueous phase) with a glass Pasteur pipette and transferred into a $15 \mathrm{~mL}$ polypropylene centrifuge tube, which is centrifuged for $2 \mathrm{~min}$ at $4000 \mathrm{rpm}$. Subsequently, the entire organic phase (approximately $2.5 \mathrm{~mL}$ ) is carefully collected and $500 \mu \mathrm{L}$ of aqueous $\mathrm{NaOH}$ solution is added in another $15 \mathrm{~mL}$ polypropylene centrifuge tube.

The back-extraction is conducted in this flask with manual stirring (approximately $3 \mathrm{~min}$ ). Phase separation is accelerated by centrifugation for $2 \mathrm{~min}$ at $4000 \mathrm{rpm}$. The organic phase is discarded and the aqueous $2 \mathrm{~mol} \mathrm{~L}^{-1}$ $\mathrm{NaOH}$ phase is taken to the quartz cuvette $(1.0 \mathrm{~cm}$ optical path, $0.7 \mathrm{~mL}$ total volume) for measurement in the 
spectrophotometer. The absorption spectra between 230 and $320 \mathrm{~nm}$ is then recorded. Figure 1 shows a typical spectrum. As the reference (100\% transmittance), $2 \mathrm{~mol} \mathrm{~L}^{-1} \mathrm{NaOH}$ solution saturated with ethyl ether is used, simulating the properties of the aqueous fraction obtained in the back-extraction. The BPA spectrum in alkaline solution has two major bands, the first centered at $242 \mathrm{~nm}$ and the second at $294 \mathrm{~nm}$, which is used for quantitative measurements due to its higher selectivity.

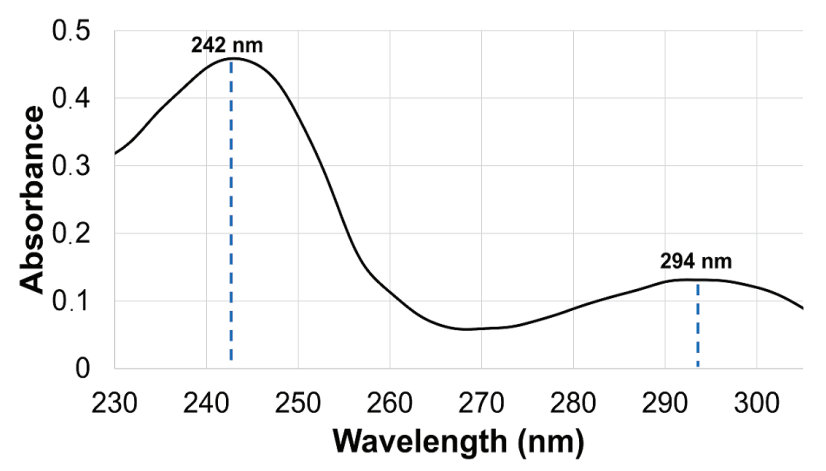

Figure 1. Spectrum in the UV region of BPA in $2 \mathrm{~mol} \mathrm{~L}^{-1} \mathrm{NaOH}$.

\section{Procedure optimization}

The extraction procedure was optimized for the variables affecting its performance. The optimization was systematically performed, seeking the best condition for the extraction method, and multivariately, to study the selectivity and a possible interaction between the variables.

\section{Sensitivity optimization}

The parameters studied in the univariate optimization were: $\mathrm{NaOH}$ concentration for back-extraction, extraction solvent, ionic strength, sample $\mathrm{pH}$, extraction time and solvent volume. Absolute recovery in each step of optimization was estimated based on the instrumental calibration curve built in aqueous $2 \mathrm{~mol} \mathrm{~L}^{-1} \mathrm{NaOH}$.

To verify the optimal $\mathrm{NaOH}$ concentration for back-extraction, a $10 \mathrm{mg} \mathrm{L}^{-1}$ BPA solution was prepared in ethyl ether, simulating the organic extract obtained from the extraction. $\mathrm{NaOH}$ concentration ranged from 0.0024 to $3.17 \mathrm{~mol} \mathrm{~L}^{-1}$. For the optimization of the extraction solvent, tests were conducted following the previously described methodology, changing only the extraction solvent. Ethyl ether, chloroform, toluene and hexane were tested. The optimization of the sample ionic strength was conducted using ethyl ether as extraction solvent. Salting-out effect was evaluated by using $\mathrm{NaCl}$ concentration equivalent to a 0.3-5.0 mol per liter of sample range. The sample $\mathrm{pH}$ ranged from 1 to 13 , using BR buffer at $0.05 \mathrm{~mol} \mathrm{~L}^{-1}$ final concentration. To optimize extraction time, tests were performed changing only the magnetic stirring time of the sample, between 0.25 and $20 \mathrm{~min}$. Solvent volume optimization was performed in the range between 4-6 mL of ethyl ether. Back-extraction volume was fixed at $500 \mu \mathrm{L}$ based on the minimal volume in the cuvette necessary for instrumental measurement.

\section{Multivariate evaluation of selectivity}

To optimize the selectivity of the method for the presence of interferents, a multivariate optimization was developed to minimize the coextraction of interferents, and/or to check the maximum concentration level of the interferents that may be present in the sample, not deteriorating method trueness. Based on the possible presence of interferents of several classes simultaneously in the sample, the multivariate optimization proves adequate and essential to verify the method's robustness. The main interferents were humic acid, phthalate esters and phenols, since they can be commonly found in natural water samples. ${ }^{16-19}$ For this study, a two-level fractional factorial design was performed, and five factors were studied: BPA concentration, sample $\mathrm{pH}$, humic acid concentration, total phthalates and total phenols.

The choice of the BPA concentration as a factor in the design was evaluated to verify the method trueness in a wide linear range, not only in a fixed high concentration, as is usually done. The minimum limit was defined as $30 \mu \mathrm{g} \mathrm{L}^{-1}$, and the maximum as $350 \mu \mathrm{g} \mathrm{L} \mathrm{L}^{-1}$ (center point at $190 \mu \mathrm{g} \mathrm{L}^{-1}$ ). The $\mathrm{pH}$ range studied was from 9 to 11 , as this is the range in which there is a decrease in the sensitivity for BPA extraction, but it may be a range in which coextraction can be minimized, especially of other phenols. The studied humic acid concentration was ranged from 0 to $10 \mathrm{mg} \mathrm{L}^{-1}$, the latter being the near-maximum value naturally found in natural waters, as shown in Table S3 (SI section) by several authors. Nevertheless, for the final experimental design, the level of humic acid ranged from 0 to $2 \mathrm{mg} \mathrm{L}^{-1}$, since in preliminary tests, samples with concentrations greater than $2 \mathrm{mg} \mathrm{L}^{-1}$ of humic acid increased significantly in recovery due to co-extraction, deteriorating recovery significantly, especially at the lowest BPA concentration. The concentration levels of phenols and phthalates were defined based on the mean of the sum of the analytes of each class in water samples ( 0.4 and $0.8 \mu \mathrm{g} \mathrm{L}^{-1}$, respectively) found in several articles in the literature (Tables S4 and S5, SI section). This average was used as the center point, with the maximum value of each factor being twice this average. Thus, the maximum values of phenols and phthalates, are, respectively, 0.8 and $1.6 \mu \mathrm{g} \mathrm{L}^{-1}$. Table S6 (SI section) shows the combination of levels for each variable, as given by the Statistica 7 software. ${ }^{20}$ Recovery was used as the response, 
being calculated by comparing the absorbance measured in each experiment with the calibration curve performed with the extraction method at each $\mathrm{pH}$ evaluated in the design.

\section{Evaluation of the main parameters of merit}

With the optimized conditions, the main quality parameters were estimated: sensitivity, intercept, correlation coefficient and the limits of detection (LOD) and quantification (LOQ). LOD and LOQ were estimated as three and ten times the standard deviation of the intercept divided by the slope, respectively. Experiments were also performed with environmental samples to verify the precision (interand intra-day repeatability) and trueness (recovery tests). The upper concentration range was $700 \mu \mathrm{g} \mathrm{L}^{-1}$ for the LLLME-UV method and for the LLME-GC-MS method (without back-extraction) was $120 \mu \mathrm{g} \mathrm{L}^{-1}$.

UV spectrophotometer calibration was also carried out, without extraction procedure, with direct reading of BPA solutions in $2 \mathrm{~mol} \mathrm{~L}^{-1} \mathrm{NaOH}$ at different concentrations in the 5 to $122 \mathrm{mg} \mathrm{L}^{-1}$ range. The purpose of this calibration was to obtain sensitivity and instrumental LODs to verify the enrichment and improvement factors of the proposed method. The enrichment factor was calculated by the ratio between the slopes of the extraction method and the instrumental sensitivity, and the enhancement factor was calculated by the ratio between the instrumental and the proposed method limits of detection.

\section{Applications of the LLLME-UV method}

\section{Water samples}

A river water sample was collected from Rio Comprido (Joinville, Santa Catarina, Brazil) and artesian well water sample was obtained as a courtesy of a property in the rural area of the same city.

Samples of tap water and mineral water were collected at the university campus. Sample of lake water was collected on the same place and filtered on qualitative paper. All samples were collected and stored in a polypropylene vial filled with zero headspace and kept in a refrigerator $\left(4{ }^{\circ} \mathrm{C}\right)$ until analysis.

Lake water fortified with humic acid in different concentrations, from 2.5 to $10.0 \mathrm{mg} \mathrm{L}^{-1}$, was used for selectivity studies and verification of limitations of the method, simulating environmental samples rich in organic matter.

\section{Lixiviation studies}

A leaching test on a plastic bottle sample (Leached I) made of polycarbonate, purchased in the local market, was performed with water extraction using a domestic microwave (Electrolux, model MEF28, power of $1150 \mathrm{~W})$. The experiment followed guidelines found in the literature. ${ }^{21}$ Shortly, the bottle was filled with reverse osmosis water $(400 \mathrm{~mL})$ and heated in a microwave for $10 \mathrm{~min}$. The aqueous extract was separated and applied in the developed method.

This first test sought to verify the possibility of applying the developed method to verify the maximum permitted limit of BPA leaching in packaging and equipment for foodstuff, regulated by Brazilian legislation (Resolution No. 17, March 17, 2008, of the Ministry of Health and the National Health Surveillance Agency (ANVISA) $)^{22}$ and internationally (Commission Regulation No. 10/2011 of 14 January 2011 of the European Union). ${ }^{23}$ These standards limit the BPA leaching to $0.6 \mathrm{mg}$ per $\mathrm{kg}$ of food. Working exclusively with pure water as a food simulant, the limits correspond to the $600 \mu \mathrm{g} \mathrm{L}^{-1} \mathrm{BPA}$ concentration.

Sample labeled as Leached II was based on a polycarbonate (PC) sample used in civil construction as roofing tiles, also following an adapted literature experiment. ${ }^{24}$ The sample was segmented into small pieces (approximately $2 \times 2 \mathrm{~cm}$ ), and an $85 \mathrm{~g}$ mass was immersed in $850 \mathrm{~mL}$ of reverse osmosis water and heated at $80^{\circ} \mathrm{C}$ for $4 \mathrm{~h}$ (evaporated water was replaced). The solids (PC sample) were removed by decantation and the aqueous fraction collected and subjected to the developed method.

\section{Results and Discussion}

\section{Optimization of extraction and back-extraction variables}

\section{Concentration of $\mathrm{NaOH}$ for re-extraction}

The back-extraction procedure was optimized by changing $\mathrm{NaOH}$ concentration. According to Figure 2a, at low $\mathrm{NaOH}$ concentrations, the back-extraction is not favored, and the migration does not occur quantitatively. The electrically neutral BPA must react with hydroxide to form the doubly electrically charged bisphenol (bisphenolate), much more soluble in water than in the solvent. Working with $\mathrm{NaOH}$ concentrations ranging from 0.0024 to $3.17 \mathrm{~mol} \mathrm{~L}^{-1}$ (theoretical $\mathrm{pH}$ from 11.4 to 14.5 ), a concentration greater than $0.04 \mathrm{~mol} \mathrm{~L}^{-1}(\mathrm{pH}>12.5)$ for a quantitative re-extraction was required, with a robustness up to the upper working range. As seen in Figure S10 (species distribution chart, SI section), above $\mathrm{pH} 12$, BPA is present in a higher percentage as the doubly deprotonated form, confirming the results obtained. As an optimum value for the work, we chose to work in $\mathrm{NaOH}$ concentration $2 \mathrm{~mol} \mathrm{~L}^{-1}$ equivalents to a theoretical $14.3 \mathrm{pH}$, due to the 
(a)

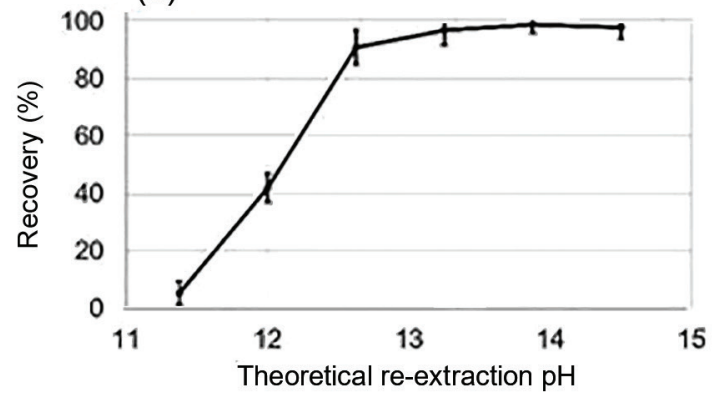

(c)

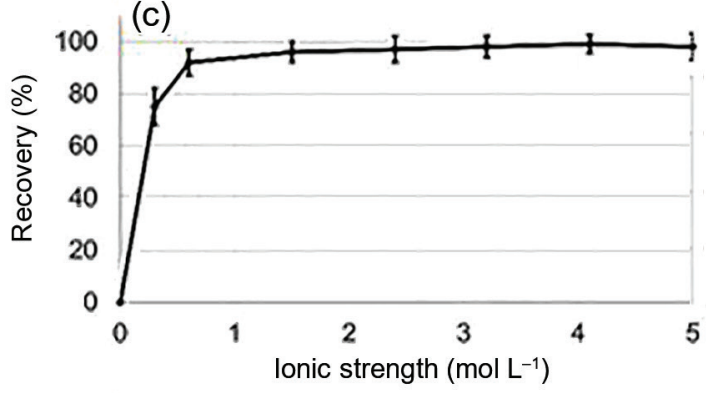

(e)

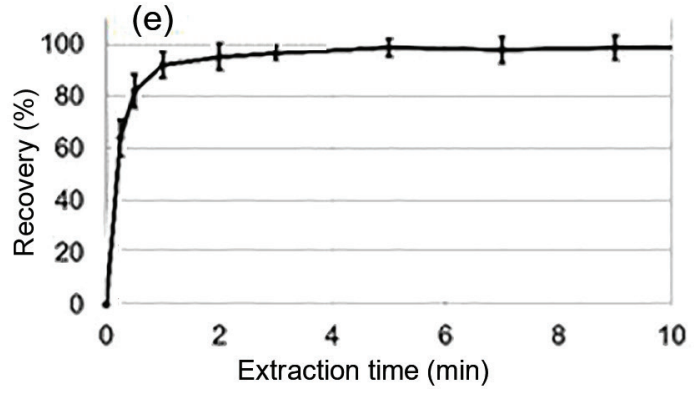

(b)

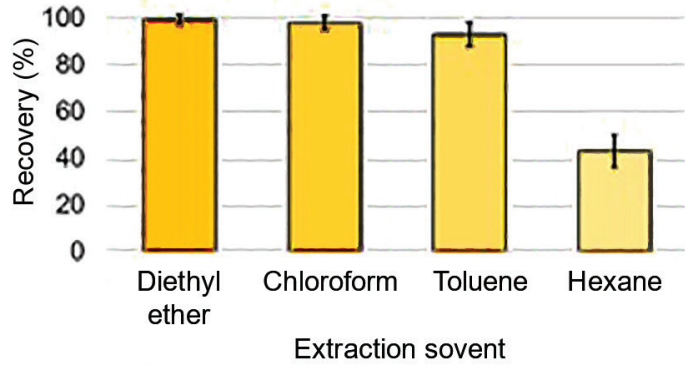

(d)

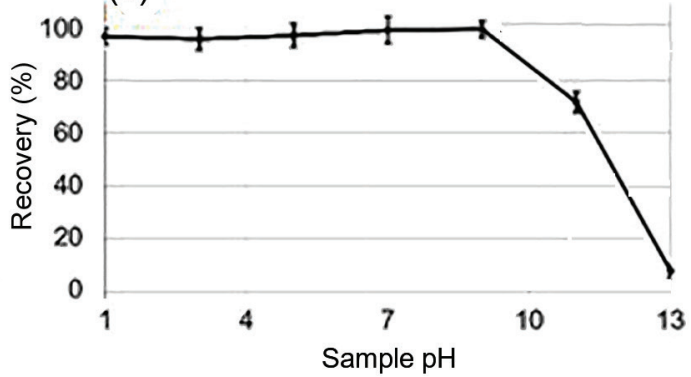

(f)

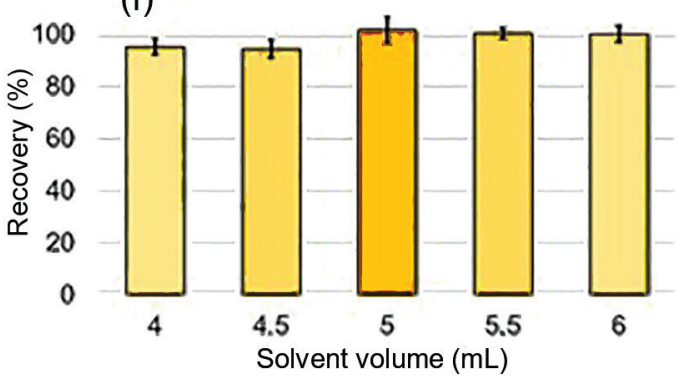

Figure 2. Optimization of the main variables affecting the proposed LLLME-UV method. (a) Concentration of NaOH for re-extraction; (b) extraction solvents; (c) ionic strength; (d) extraction $\mathrm{pH}$; (e) extraction time; (f) solvent volume.

higher phase separation velocity at this high ionic strength, which makes the method faster.

\section{Extraction solvent}

Figure $2 b$ shows the effect of different extraction solvents on BPA recovery from water samples. Among the extractive solvents evaluated, hexane (the most nonpolar alternative) recovered less than $50 \%$. For the remaining options, the best alternatives are the use of diethyl ether and chloroform, with recoveries greater than $90 \%$. The use of chloroform, however, is more difficult to work with due to its high density when compared to the aqueous phase, since it is necessary to collect the solvent in the bottom of the extraction flask (100 mL volumetric flask). Thus, we decided to use diethyl ether due to its lower density when compared to the aqueous solution and lower toxicity when compared to chloroform.

\section{lonic strength}

The evaluation of the ionic strength (Figure 2c) allows to find a condition of wide range of ionic strength (from 1 to $5 \mathrm{~mol} \mathrm{~L}^{-1}$ ) in which the extraction is quantitative. At very low ionic strengths, the effect of decreasing the solubility of BPA in water (salting-out effect) may not be enough to allow the extraction of aqueous BPA to the organic solvent. We attribute the best condition of ionic strength as $2 \mathrm{~mol} \mathrm{~L}^{-1} \mathrm{NaCl}$, since this concentration leads to a fast phase separation and high BPA recovery.

\section{Extraction $\mathrm{pH}$}

As already described, BPA has different abundances in its neutral form as the sample $\mathrm{pH}$ changes (Figure S10, SI section). Thus, the effect of the sample $\mathrm{pH}$ on its extraction efficiency was verified (Figure 2d). Extractions performed with a sample with $\mathrm{pH}$ lower than 9 are not statistically different. Under these conditions, BPA is totally in its electrically neutral form, favoring its extraction by the organic solvent. We attributed $\mathrm{pH} 9$ to the optimized condition. Nevertheless, the use of $\mathrm{pH} 10$ and 11 may be applicable, but there will be a slight loss in sensitivity. 


\section{Extraction time}

The extraction time was also optimized, since an analytical method should be as fast and practical as possible (Figure 2e). Extraction times greater than 3 min were found to be enough to establish the BPA partition equilibrium between the aqueous and organic phases, and that after this time the recovery of the analyte is statistically the same. We decided to choose the time of $10 \mathrm{~min}$ for effective extraction, since the extraction conditions depend on the degree of stirring on the flask used and the magnetic stirrer power, ensuring that the equilibrium can be achieved even with small variations in the effectiveness of stirring.

\section{Solvent volume}

The solvent volume used was also studied to minimize its use (Figure 2f). We noticed that there is no significant variation of the extraction efficiency with the variation of the volume of solvent used in the 4 to $6 \mathrm{~mL}$ range, recoveries ranging from 90 to $105 \%$. The volume chosen as the optimum one was $6 \mathrm{~mL}$, since the separation phase is adequately fast with this volume and recovery is maximized. Working with a lower volume of extraction solvent is also possible, improving method enrichment factor when no back-extraction is used, i.e., when the organic phase is directly analyzed by other instrumentation such as GC.
It should be emphasized that direct measurement of ether extracts by UV at $294 \mathrm{~nm}$ was not possible due to high absorbance value of such solvent at this wavelength.

\section{Selectivity multivariate analysis}

Figure 3 shows recovery results in the lowest BPA condition, 30 and $350 \mu \mathrm{g} \mathrm{L}{ }^{-1} \mathrm{BPA}$ and $\mathrm{pH} 10$, at the center point of concentration of the interferents.

In the first condition, the concentration of humic acid ranging from 0 to $2 \mathrm{mg} \mathrm{L}^{-1}$ does not affect the selectivity of the method, whose recovery ranges from 110 to $115 \%$ throughout the range. Such behavior is not observed for phenols and phthalates: high concentrations of these interferents raises the recovery results, indicating loss of selectivity with the overestimated measurement of absorbance (however, for a high concentration of BPA, interferents are not significant). This fact can be understood because of the structural similarity with BPA: phenols tend to be co-extracted by the method, also considering that they have a significant molar absorptivity at $294 \mathrm{~nm}$, as can be observed in Figure S11 (SI section).

Nonetheless, the presence of studied interferents at their natural average concentration in aqueous environmental samples allows acceptable recovery. ${ }^{25}$ That is, the method
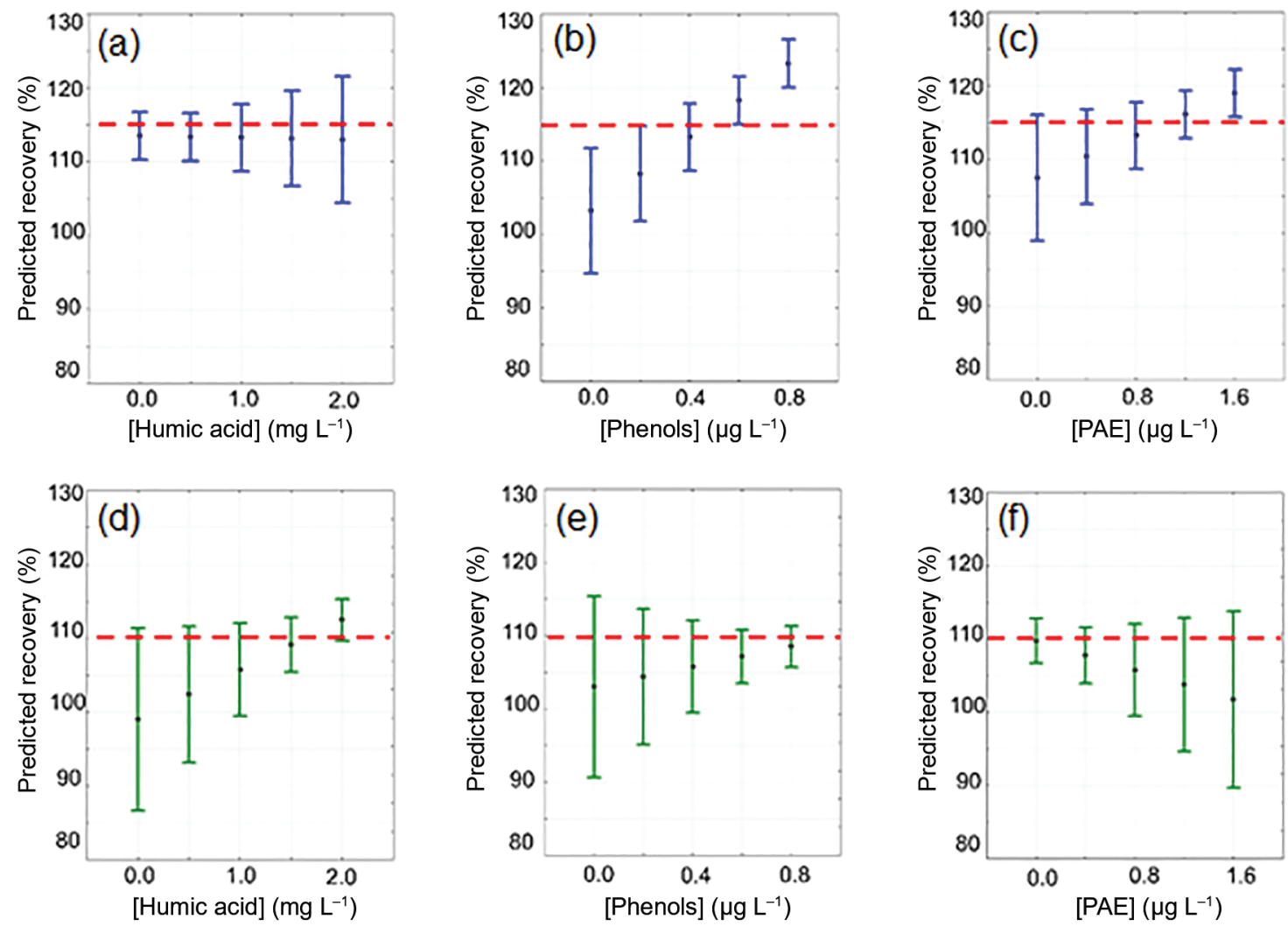

Figure 3. Response profile predicted by the experimental design: BPA (a-c) 30 and (d-f) $350 \mu \mathrm{L} \mathrm{L}^{-1}$, $\mathrm{pH} 10,1 \mathrm{mg} \mathrm{L}^{-1}$ for humic acid, $0.4 \mu \mathrm{g} \mathrm{L} \mathrm{L}^{-1}$ for total phenols and $0.8 \mu \mathrm{g} \mathrm{L}^{-1}$ for phthalates; and their relationship with the maximum allowed recovery (dashed red line). 
Table 1. Evaluation of the main quality parameters of both instrument (without extraction) and the LLLME-UV proposed method

\begin{tabular}{lcc}
\hline Parameter & Method calibration $(\mathrm{n}=24)$ & Instrumental calibration $(\mathrm{n}=12)$ \\
\hline Slope / $\left({\left.\mathrm{L} \mu \mathrm{g}^{-1} \mathrm{~cm}^{-1}\right)}^{-}\right.$ & $3.37 \times 10^{-3} \pm 0.02 \times 10^{-3}$ & $0.0215 \times 10^{-3} \pm 0.0001 \times 10^{-3}$ \\
Intercept & $0.015 \pm 0.004$ & $-0.002 \pm 0.008$ \\
Determination coefficient $\left(\mathrm{R}^{2}\right)$ & 0.9996 & 0.9999 \\
Limit of detection / $\left.(\mu \mathrm{g} \mathrm{L})^{-1}\right)$ & 3.5 & 1050 \\
Limit of quantification / $(\mu \mathrm{g} \mathrm{L}-1)$ & 12 & 3500 \\
\hline
\end{tabular}

LLLME-UV: liquid-liquid-liquid microextraction UV-Vis spectrophotometry

can be sufficiently accurate at $30 \mu \mathrm{g} \mathrm{L^{-1 }}$ or higher even with the simultaneous influence of different contaminants (humic acid, phenols and phthalates).

Then, based on both the univariate optimization experiments and the multivariate study, the optimal sample preparation condition is described: for $85 \mathrm{~mL}$ of sample, adjusted at $\mathrm{pH} 10$ with $5 \mathrm{~mL}$ of $0.4 \mathrm{~mol} \mathrm{~L}^{-1}$ BR buffer and ionic strength $2 \mathrm{~mol} \mathrm{~L}^{-1}$ with $\mathrm{NaCl}$, the extraction is performed with $6 \mathrm{~mL}$ of diethyl ether for $10 \mathrm{~min}$ under magnetic stirring, followed by back-extraction of the entire organic extract with $0.5 \mathrm{~mL}$ of $2 \mathrm{~mol} \mathrm{~L}^{-1} \mathrm{NaOH}$. The maximum concentrations tolerated by the method are $2 \mathrm{mg} \mathrm{L}^{-1}$ of humic acid, $0.4 \mu \mathrm{g} \mathrm{L} \mathrm{L}^{-1}$ of phenols and $0.8 \mu \mathrm{g} \mathrm{L}-1$ of phthalates, either individually or concomitantly.

\section{Evaluation of the main parameters of merit}

The main quality parameters of the LLLME-UV method are described in Table 1. Instrumental calibration was also performed for comparison.

The improvement factor is 300 , i.e., the application of the method reduces the minimum detectable concentration by 300 times. The enrichment factor of the method is 155 . This value approaches the expected maximum factor of 170 (considering a 85 to $0.5 \mathrm{~mL}$ phase ratio, between sample and final aqueous phase), indicating that most of the BPA present in the sample is actually extracted, confirming the improvement of sensitivity by the application of the method. The ratio between the obtained and the expected maximum results in $91 \%$, indicating a very high absolute recovery. For the calibration of the method, especially, satisfactory parameters were obtained, such as the limit of detection in the $\mu \mathrm{g} \mathrm{L}^{-1}$ range (Table 1) and excellent correlation coefficient. The merit parameters presented excellent values, both in terms of accuracy and precision, as well as the limit of detection and linear range, in line with ANVISA $^{22}$ and European Union ${ }^{23}$ resolutions regarding BPA leaching for food (specifically for water).

The method presented excellent intra-day precision (Table 2), analyzed in five different levels by the relative standard deviation (RSD). Inter-day precision also showed excellent results, especially when compared with the maximum acceptable RSD intra-lab, given by Horwitz. ${ }^{26}$

Table 2. Evaluation of LLLME-UV repeatability and intermediate precision and their comparison with the acceptable limit $^{26}$

\begin{tabular}{lccc}
\hline \multirow{2}{*}{$\mathrm{BPA} /\left(\mu \mathrm{g} \mathrm{L}^{-1}\right)$} & \multicolumn{2}{c}{$\mathrm{RSD}(\mathrm{n}=3) / \%$} & Acceptable \\
\cline { 2 - 3 } & Repeatability & $\begin{array}{c}\text { Intermediate } \\
\text { precision }\end{array}$ & \begin{tabular}{c} 
limit $^{\mathrm{a}}$ \\
\hline 7.0
\end{tabular} \\
18.8 & - & 22.5 \\
15.0 & 6.3 & - & 20.1 \\
30.0 & 5.0 & 7.8 & 18.1 \\
120.0 & 2.8 & 4.0 & 14.7 \\
700.0 & 3.1 & 2.8 & 11.3 \\
\hline
\end{tabular}

${ }^{\mathrm{a}}$ According to Horwitz. ${ }^{26}$ LLLME-UV: liquid-liquid-liquid microextraction UV-Vis spectrophotometry; BPA: bisphenol A; RSD: relative standard deviation.

All precision tests fit within the maximum limits set by the AOAC, ${ }^{27}$ indicating the quality of the method.

\section{Method application}

The method was applied to different samples, and a summary of the results is shown in Table 3 .

BPA concentration was below the limits of the detection method in the first five samples. Recovery and repeatability tests for these samples are in accordance with the expected results. ${ }^{25-27}$ The recovery range varied between 98.9 and $113.0 \%$ among the three concentration levels studied and repeatability from 1.5 to $10.3 \%$.

Microwave plastic cup leaching test (Leached I) did not result in detectable presence of BPA in the aqueous sample. Precision and recovery tests have been successfully performed. Thus, this method can be used to evaluate the migration of BPA from plastic packaging following the regulations of the Brazilian Ministry of Health, ${ }^{22}$ as well as the European Union ${ }^{23}$ resolution. The application of the method is essential for this case, since the direct 
Table 3. Summary of LLLME-UV method applications, recovery and precision assays

\begin{tabular}{lcccc}
\hline \multirow{2}{*}{ Sample } & $\mathrm{BPA} \pm \mathrm{SD}^{\mathrm{a}} /\left(\mu \mathrm{g} \mathrm{L}^{-1}\right)$ & \multicolumn{3}{c}{ Recovery $\pm \mathrm{RSD} / \%$} \\
\cline { 3 - 5 } Bottled water & $<\mathrm{LOD}$ & $30 \mu \mathrm{g} \mathrm{L}^{-1}$ & $120 \mu \mathrm{g} \mathrm{L}^{-1}$ & $100 \mu \mathrm{g} \mathrm{L}^{-1}$ \\
Tap water & $<\mathrm{LOD}$ & $113.0 \pm 7.9$ & $104.3 \pm 4.0$ & $103.2 \pm 2.9$ \\
Lake & $<\mathrm{LOD}$ & $103.7 \pm 10.3$ & $100.8 \pm 2.1$ & $104.0 \pm 5.1$ \\
River & $<\mathrm{LOD}$ & $105.8 \pm 7.5$ & $107.1 \pm 1.6$ & $105.9 \pm 4.0$ \\
Artesian well & $<\mathrm{LOD}$ & $109.4 \pm 2.2$ & $106.8 \pm 1.5$ & $101.5 \pm 2.8$ \\
Leached I & $<$ LOD & $101.7 \pm 3.5$ & $108.6 \pm 4.0$ & $105.1 \pm 4.9$ \\
Leached II & $104.0 \pm 4.4$ & $98.9 \pm 4.1$ & $101.3 \pm 3.0$ \\
Allowed recovery $/ \%$ & $45.0 \pm 2.9$ & $160.9 \pm 3.2$ & $121.9 \pm 3.5$ & $102.3 \pm 3.0$ \\
Acceptable precision $(\mathrm{RSD})^{\mathrm{c}} / \%$ & & $60-115$ & $80-110$ & $80-110$ \\
\hline
\end{tabular}

${ }^{a}$ Concentration obtained by liquid-liquid microextraction gas chromatography-mass spectrometry (LLME-GC-MS) $=28.4 \pm 1.8 \mu \mathrm{g} \mathrm{L}^{-1}$; ${ }^{\mathrm{b}}$ according to Rambla-Alegre et al. ${ }^{25}$ caccording to Horwitz. ${ }^{26}$ LLLME-UV: liquid-liquid-liquid microextraction UV-Vis spectrophotometry; BPA: bisphenol A; SD: standard deviation; RSD: relative standard deviation; LOD: limit of detection.

measurement of the leach sample by the instrument does not reach the limit of detection required by both Brazilian and EU regulations (Table 1). ${ }^{22,23}$

For the sample labeled as Leached II, $45.0 \mu \mathrm{g} \mathrm{L}{ }^{-1} \mathrm{BPA}$ was determined by LLLME-UV method. In contrast, the experiment performed by GC-MS showed a divergent result, namely, $28.4 \mu \mathrm{g} \mathrm{L}^{-1}$. In this case, therefore, a lack of selectivity of the LLLME-UV method was observed, with BPA concentration overestimated at $58 \%$. Figure S12 (SI section) shows the spectrum obtained by analyzing the extract of the polycarbonate leach sample. We could observe a similarity with the BPA spectrum (Figure 1), with displacement of the maximum absorption wavelengths to a more energetic region, indicating a change in the chemical composition of the extract. This variation can be caused by the leaching of other components of the analyzed plastic material such as other monomers and additives used in its manufacture. Although analysis of this high temperature leaching polycarbonate sample did not yield accurate results, we should note that it provides useful information to the analyst: it served as a strong indication of BPA presence and of the need for a more detailed examination (such as GC-MS analysis) even without reporting its exact concentration. Similarly, it served to prove that other compound(s) leached from this material.

A univariate test was conducted to evaluate the method limitations regarding samples with high organic matter content. Figure S13 (SI section) shows the pattern of absorbance as a function of added humic acid in the sample not containing BPA. For analysis of waters with low organic matter, there is a safe limit of variation of analytical response (absorbance) without the false detection of BPA.
In specific cases, in which the sample has humic acid concentrations higher than $2.5 \mathrm{mg} \mathrm{L}^{-1}$, BPA may be erroneously detected due to an absorbance greater than 0.05. Extreme cases, in which the concentration exceeds $10 \mathrm{mg} \mathrm{L}^{-1}$, BPA may be falsely quantified, indicating a severe error.

Nevertheless, the method developed allows accurate analysis of environmental samples of low organic content, corresponding especially to tap, bottled water, wells, and to fairly clean rivers and lakes.

\section{Conclusions}

The LLLME-UV method proposed in this study showed a satisfactory applicability scope of types of aqueous samples, with low cost and high efficiency, and some limitations in terms of humic acid, phenols and phthalates concentration in the samples. The main quality parameters of the LLLME-UV method presented excellent values, both in terms of accuracy, precision and limits of detection.

The method was shown to be useful for the study of BPA leaching for food simulant, being in line with ANVISA and European Union resolutions. Furthermore, the method was shown to be an excellent alternative for both UV detections, serving for qualitative (screening) or quantitative purposes, and GC-MS separation/detection, for a more unequivocal identification and quantification in the case of much more complex samples.

\section{Supplementary Information}

Supplementary data are available free of charge at http://jbcs.sbq.org.br as PDF file. 


\section{Acknowledgments}

The authors are grateful to the Conselho Nacional de Desenvolvimento Científico e Tecnológico (CNPq) and Fundação de Amparo à Pesquisa e Inovação do Estado de Santa Catarina (FAPESC) for their financial support. This study was also financed in part by the Coordenação de Aperfeiçoamento de Pessoal de Nível Superior, Brazil (CAPES), finance code 001. The authors are especially grateful to the Universidade do Estado de Santa Catarina for sponsoring the publication of this work.

\section{References}

1. Sauvé, S.; Desrosiers, M.; Chem. Cent. J. 2014, 8, 15.

2. https://www.researchandmarkets.com/research/4xx8j9/ bisphenola_a, accessed in March 2020.

3. Flint, S.; Markle, T.; Thompson, S.; Wallace, E.; J. Environ. Manage. 2012, 104, 19.

4. Michałowicz, J.; Environ. Toxicol. Pharmacol. 2014, 37, 738.

5. Dodds, E. C.; Goldberg, L.; Lawson, W.; Robinson, R.; Nature 1938, 141, 247.

6. Schug, T. T.; Janesick, A.; Blumberg, B.; Heindel, J. J.; J. Steroid Biochem. Mol. Biol. 2011, 127, 204.

7. Prieto, A.; Schrader, S.; Moeder, M.; J. Chromatogr. A 2010, 1217, 6002.

8. Liu, R.; Zhou, J. L.; Wilding, A.; J. Chromatogr. A 2004, 1022, 179.

9. Iparraguirre, A.; Prieto, A.; Navarro, P.; Olivares, M.; Fernández, L. Á.; Zuloaga, O.; Anal. Bioanal. Chem. 2011, 401, 339.

10. Guitart, C.; Readman, J. W.; Anal. Chim. Acta 2010, 658, 32.

11. Xu, Z.; Wu, Q.; Duan, Y.; Yang, M.; Ou, M.; Xu, X.; J. Braz. Chem. Soc. 2017, 28, 1475.

12. Li, J.; Zhang, X.; Liu, Y.; Tong, H.; Xu, Y.; Liu, S.; Talanta 2013, 117, 281 .

13. Chu, G.; Cai, W.; Shao, X.; Talanta 2015, 136, 29.

14. Xu, J.; Li, Y.; Bie, J.; Jiang, W.; Guo, J.; Luo, Y.; Shen, F.; Sun, C.; Microchim. Acta 2015, 182, 2131.
15. Yıldırım, E.; Gürkan, R.; Altunay, N.; Food Anal. Methods 2017, 10, 1765.

16. Amiridou, D.; Voutsa, D.; J. Hazard. Mater. 2011, 185, 281.

17. Gatselou, V. A.; Giokas, D. L.; Vlessidis, A. G.; Anal. Chim. Acta 2014, 812, 121.

18. Sánchez-Avila, J.; Tauler, R.; Lacorte, S.; Environ. Int. 2012 , $46,50$.

19. Zaki, G.; Shoeib, T.; Sci. Total Environ. 2018, 618, 142.

20. Statistica, 7.0; StatSoft, Inc., Tulsa, OK, USA, 2004.

21. Biedermann-Brem, S.; Grob, K.; Eur. Food Res. Technol. 2009, 228,679

22. Agência Nacional de Vigilância Sanitária (ANVISA); Resolução No. 17, de 17 de Março de 2008; Dispõe sobre Regulamento Técnico sobre Lista Positiva de Aditivos para Materiais Plásticos Destinados à Elaboração de Embalagens e Equipamentos em Contato com Alimentos; ANVISA: Brasília, 2008. Available at bvsms.saude.gov.br/bvs/saudelegis/ anvisa/2008/res0017_17_03_2008.html, accessed in March 2020.

23. European Commission; Commission Regulation (EU) No. 10/2011 of 14 January 2011 on Plastic Materials and Articles Intended to Come into Contact with Food; Official Journal of the European Union: Brussels, 2011. Available at https://eur-lex.europa.eu/legal-content/EN/ ALL/?uri=CELEX\%3A32011R0010, accessed in March 2020.

24. D’Antuono, A.; Dall'Orto, V. C.; Lo Balbo, A.; Sobral, S.; Rezzano, I.; J. Agric. Food Chem. 2001, 49, 1098.

25. Rambla-Alegre, M.; Esteve-Romero, J.; Carda-Broch, S.; J. Chromatogr. A 2012, 1232, 101.

26. Horwitz, W.; Anal. Chem. 1982, 54, 67.

27. AOAC Official Methods of Analysis; Appendix F: Guidelines for Standard Method Performance Requirements; AOAC International: Gaithersburg, MD, 2016. Available at http://www. eoma.aoac.org/app_f.pdf, accessed in March 2020.

Submitted: October 30, 2019 Published online: March 13, 2020 